\title{
Corrida Armamentista: Estudo sobre a dinâmica armamentista na América do Sul de 2003 a 2007 e suas consequências atuais
}

\author{
Richard William Baviera Nunes ${ }^{1}$
}

\section{Resumo}

Este trabalho busca analisar a hipótese de uma corrida armamentista no continente sulamericano. Os recentes avanços de projetos bélicos do Brasil e de outros países levantam a questão da existência deste fenômeno no continente. O procedimento de pesquisa se dá por meio de um levantamento das principais teorias quantitativas e qualitativas acerca de corridas armamentistas e, depois, com relação a dados das compras bélicas, rivalidades estratégicas e indústrias de armamentos nascentes. Estes dados são combinados para analisar se há ou não uma corrida armamentista em curso na América do Sul. Confirmada a incidência de momentos de corrida armamentista na região, o artigo busca avaliar os possíveis resultados destes.

Palavras Chave: Corrida Armamentista; América do Sul; Segurança; Realismo

\section{Abstract}

The work analyses the hypothesis of an arms race in the South American continent. Recent advances in military projects in Brazil and in other countries raise questions about the existence of an arms race phenomenon in the continent. The research proceeds through a survey of the main qualitative and qualitative theory's concerning arms races, as well as through data of weapon purchases, strategic rivalries and emerging armaments industries. This data is combined to analyse if an arms race is or not in course in South America. Confirmed this first hypothesis, we articled dwells on the phenomenon possible outcomes.

Keywords: Arms Race, South America, Security and Realism.

\footnotetext{
${ }^{1}$ Este artigo corresponde ao resultado de uma pesquisa de Iniciação Científica e ao Trabalho de Conclusão de Curso apresentado à Universidade Anhembi Morumbi (SP), para obtenção do grau no curso de Relações Internacionais (2014). Atualmente o autor trabalha na área de segurança do Comité Olímpico como Especialista em Relações Internacionais e Segurança.
} 


\section{Introdução}

No ano de 2012 os aviões Mirage III e 2000 da força área brasileira foram aposentados, seu sucessor só seria escolhido no final do seguinte ano. Durante este período houve algumas discussões acerca do rearmamento das forças armadas do Brasil e da América do Sul. É fato que o gasto em defesa dos países do continente aumentou nos últimos anos (VILLA e VIGGIANO, 2012). Os arsenais, comprovadamente obsoletos e o crescimento econômico foram apontados como os motivos para este crescimento, porém, isto não leva em conta um fator crucial: o fato de existirem rivalidades estratégicas ativas entre os países sul-americanos. Isto gera uma questão: Haveria uma escalada armamentista dentro da América do Sul?

Podemos levantar a seguinte hipótese, a de que a corrida armamentista existe pontualmente entre os países de acordo com suas rivalidades estratégicas. Nesse contexto, consideramos então que pode haver relações de cooperação, como ocorre com a relação entre Brasil e Argentina, e relações de conflito, como ocorrem entre Venezuela e Colômbia. Acrescenta-se também a possibilidade de tensões na fronteira amazônica causadas por atores não estatais e pela presença estrangeira. Alguns estudos mais alinhados aos setores nacionalistas do debate, como os do autor brasileiro Francisco Carlos Teixeira da Silva (2007), apontam para estes atores estrangeiros e não estatais como principal ameaça ao Brasil.

Sintetizando a hipótese, a corrida armamentista ocorre pontualmente de acordo com as rivalidades estratégicas. Seu fator de detonação teria sido a presença estrangeira no continente que veio apoiar o combate a focos de instabilidade interna, assim suas ações causaram insegurança nos países sul-americanos iniciando uma corrida armamentista (SILVA, 2007).

Então o objetivo geral deste artigo será analisar a corrida armamentista na primeira década do século XXI, levantando os dados empíricos necessários. Mais especificamente se analisará as principais teorias sobre o tema como base teórica e, se a hipótese da corrida armamentista se confirmar utilizaremos a base teórica e os dados empíricos para analisar possíveis efeitos e fins que ela poderá ter. A relevância de tal estudo reside no fato que o tema tem sido debatido esporadicamente nos últimos anos, sendo que tensões e escaladas armadas são comuns no continente no decorrer de sua história. Há também o fator dos projetos de rearmamento por parte do Brasil que fazem os estudos de segurança importantes neste período que vivemos. 
$\mathrm{Na}$ metodologia empregaremos tanto teorias quantitativas quanto qualitativas e um levantamento de dados listando as rivalidades estratégicas, orçamentos e armamentos. Após de se fazer isso, iremos juntar a teoria com os dados empíricos para gerar resultados e, posteriormente, fazer previsões dos possíveis cenários futuros nas considerações finais.

\section{A perspectiva teórica}

Primeiramente, a teoria de corrida armamentista está ligada à teoria realista das Relações Internacionais. $\mathrm{O}$ estado é um ator coeso e racional que busca poder no sistema internacional anárquico, sendo este estado identificado como uma caixa preta dentro do modelo de bola de bilhar buscando estabilidade interna e externa.

A Guerra Fria e suas escaladas seriam um terreno fértil para estudos de corridas armamentistas dentro do escopo do realismo. O estudo se dividiria em teorias quantitativas e qualitativas, sendo que na Guerra Fria, os cálculos de força quantitativos seriam mais predominantes. Os modelos principais seriam o do "Dilema do Prisioneiro", o de "Espiral" e o de "Detenção" (KYDD, 2000). O "Dilema do Prisioneiro" se relaciona diretamente com a teoria dos jogos, em que o dilema trata de como a busca por segurança pelos estados gera insegurança em seus vizinhos. Já a "Teoria dos Jogos" trata de como os atores agem individualmente ou em conjunto de acordo com suas preferências, ou seja, a cooperação é uma forma de maximizar os ganhos dos atores.

Segundo este modelo, a corrida armamentista passa a ser identificada como um equilíbrio não cooperativo e o controle de armas como um equilíbrio cooperativo que superaria o outro cenário em decorrência de seus ganhos (KYDD, 2000). Porém tal modelo entraria em contradição por não levar em conta as preferências estruturais dos atores. Os atores não valorizariam os ganhos da cooperação e a possibilidade de ameaça no futuro fazem com que a cooperação não seja atrativa. Kydd (2000, pp. 230) aponta:

Essas estruturas de recompensas podem aparecer em corridas armamentistas por conta de sistemas de defesa decisivos, como os navios Dreadnought antes da Primeira Guerra Mundial e as armas nucleares de depois da Segunda Guerra Mundial. Estar sem tais armas quando seu adversário as tem pode ser visto como desastroso, e a cooperação pode ser difícil de atingir.

A alternativa seria o modelo de "Espiral", este se baseia na premissa de que os medos mútuos entre os estados causam a corrida armamentista (JERVIS 1976 apud KYDD, 2000). 
Os estados estão satisfeitos com o status quo do sistema internacional, porém possuem medos de que outros tenham intenções agressivas, e com isso passam a construir um grande arsenal causando medos e desconfianças em outros estados levando a uma guerra preventiva (KYDD, 2000). Em contrapartida haveria o modelo de "Detenção", associado aos Hawks da Guerra Fria, os defensores da política de vigilância e reação durante esse período. Este modelo se baseia na premissa de que um estado em ascensão constrói um grande arsenal para fazer frente a uma potência já estabelecida, e esta, por sua parte, reforça seu arsenal já existente a fim de fazer frente ao novo adversário.

A partir daí o comportamento da corrida armamentista passa a interagir com as opções de barganha e guerra (KYDD, 2000). Essa interação ocorre da seguinte maneira: as negociações entre estados falham e estes recorrem à guerra, os que tiverem mais ganhos na guerra terão um maior poder de barganha futuro. Assim sendo, a corrida armamentista serve para garantir vitorias na guerra e o aumento do poder de barganha do estado(KYDD, 2000).

Tais modelos, assim como a teoria realista, encontraram um terreno fértil na Guerra Fria, porém, o fim desta sem um conflito trouxe duras críticas a estes modelos e à corrente realista. Ainda assim, as desilusões com os modelos liberais nos anos 90 trariam de volta o Realismo e os estudos de corrida armamentista, dessa vez, focando em um fator já estudado no período: o fator qualitativo.

O primeiro modelo a ser analisado é o de "identificação de rivalidades estratégicas" de William R. Thompson (2001). Primeiramente, a concepção de uma rivalidade estratégica é que esta tem ligação direta com conflitos, porém isto não é via de regra um conflito, pois o mesmo pode gerar muitos gastos cujos ganhos não o cobrirão. Desta forma o conflito pode ser substituído por uma rivalidade aonde pode haver tensão e cooperação na interação (THOMPSON, 2001). O modelo considera tanto fatores quantitativos quanto qualitativos buscando identificar as rivalidades estratégicas entre atores em decorrência de seus objetivos materiais e não materiais.

Assim, se identifica a quantidade de rivalidades que ocorreram entre os atores e quantas escalonaram para um conflito direto ou foram resolvidas diplomaticamente, levando em conta fatores qualitativos como decisões da liderança, fatores históricos e domésticos (THOMPSON, 2001). Vale ressaltar que este modelo somente identifica rivalidades que causam corridas armamentistas, não estas em si, pois na rivalidade estratégica o conflito pode 
ocorrer em campos diferentes. Por outro lado, o conflito militar pode ocorrer sem uma escalada antes, em especial em mundo aonde agressões indiretas podem levar diretamente ao conflito.

Desta forma, o modelo de rivalidades evoluiu e passou a observar a corrida armamentista dentro da concepção das rivalidades estratégicas e resolvendo um antigo problema dos modelos de "Detenção" e "Espiral". Estes acreditavam que as escaladas armadas eram naturais do sistema internacional ignorando os motivos pelos quais o estado entraria em tais escaladas, assim o novo modelo procura saber os objetivos que levam o estado a se lançar em uma escalada armada (RIDER, 2009).

Considera-se, então, que tal objetivo é crucial e, com isso, valioso o bastante para embarcar em uma corrida armamentista. Desta forma o estado busca avaliar se está recebendo um sinal dos seus rivais quando estes aumentam seu poder militar, para resolver a questão no âmbito de corridas armamentistas (RIDER, 2009). A partir daí, o estado tem duas opções: resistir às investidas do adversário por outros meios, ou aumentar seu arsenal resolvendo a rivalidade com uma escalada.

Os atores evitarão o conflito, porém, se o objetivo for crucial a corrida armamentista pode ser mais atrativa para se resolver a rivalidade. Rider (2009) aponta que tal objetivo crucial é a questão territorial, sendo a geografia dos territórios um causador de conflitos internacionais (VASQUEZ, 1993 apud RIDER, 2009). A partir daí, a disputa de território pode ser classificada em três categorias: "Tangíveis", "Intangíveis" e de "Reputação" (HENSEL, 2000 apud RIDER, 2009). A categoria “Tangível” remete aos recursos que o território pode oferecer, não se limitando somente a recursos naturais, mas também à segurança que este pode oferecer.

A categoria "intangível" lida com questões não materiais como história, valores culturais e de etnia, uma dada população pode considerar o território sua pátria mãe e com isso se apegar a ele mesmo após a sua falência (RIDER, 2009). No caso da categoria de "Reputação" esta gira em torno da aquisição de territórios, em que ao se adquiri-los se encoraja aquisições futuras, sendo que se as questões territoriais não forem resolvidas estas colocarão em perigo a segurança do estado.

Ainda na área qualitativa um modelo descrito por Colin S. Gray (1971) buscou relevar outras características qualitativas. A primeira dessas é que a corrida armamentista não é 
somente uma exclusividade de estados, mas também de atores não estatais; Gray (1971, pp. 39) coloca:

\begin{abstract}
Deve ser notado que corridas armamentistas não ocorrem somente entre estados e coalizões de estados. Aqueles cuja visão está firmemente fixada em grandes questões de interestado tende a negligenciar a violência interestado e a preparação para esta. Isto é provavelmente mundano, mas ainda assim uma correta explicação para o foco interestado de praticamente todos os escritos relacionados a corridas armamentistas. $\mathrm{O}$ armamento concorrente entre os voluntários irlandeses e de Ulster entre 1910 e 1914 parece ser um caso claro de relações armamentistas competitivas que poderíamos desejar.
\end{abstract}

Tal afirmação se deve ao fato de ser difícil distinguir as ações domésticas das ações externas. A tipologia do modelo passa a avaliar fatores como: tipos e qualidades de armamentos, uso de grupos não estatais por outros países, e em que forma o PIB é gasto nesta questão (GRAY, 1971). Após observar a tipologia o modelo avalia as estratégias de corrida armamentista que podem estar sendo empregadas, estas se dividem em: "Inferioridade Clara", onde o estado tem clara inferioridade perante seu adversário, mas se prepara nacionalmente, de uma forma quase suicida, a fim de dissuadir o adversário pelos danos que podem ocorrer no confronto; "Inferioridade Marginal", quando o estado busca ao menos uma paridade com o adversário, pois entende os riscos e altos custos da escalada armada; "Paridade", esta pode ser uma forma de desacelerar a corrida, sendo que se somente busca a igualdade em termos de quantidade e qualidade de armamentos os estados podem ganhar uma boa posição para negociar suas diferenças; "Superioridade Marginal”, quando se busca ter ao menos uma leve vantagem frente ao adversário, para se ter mais chances de vitória em um possível conflito; "Superioridade Clara", nesta estratégia o estado pode utilizar o seu poder já existente para ter ganhos no âmbito diplomático, porém os outros estados poderão buscar táticas mais desesperadas para poder alcançar a superioridade do adversário (GRAY, 1971).

O modelo conclui com um estudo das possíveis consequências da corrida armamentista, estas se dividem em: "Guerra", quando as tensões chegam a um ponto de inflexão aonde o conflito é iminente, o risco de falência do estado em decorrência da corrida faz com que a guerra seja mais compensatória ou a criação de um dispositivo suicida que destruiria ambos evitando a guerra (este caso segue a lógica da Guerra Fria, melhor representado na sátira do filme Dr. Strangelove de Stanley Kubrick); "Falência" ou "Exaustão", onde o estado implode por não aguentar a pressão de uma corrida armamentista sobre seus recursos; "Vitória" ou "Derrota", onde o estado é vitorioso sobre o adversário quando este não consegue superar o 
outro em dado elemento militar e ter poder de barganha, o vitorioso passa a ter uma posição de fazer o derrotado assinar um acordo favorável a ele; "Acordo vindo de paridade", quando os estados chegam a um acordo por conta da igualdade de números, mesmo que estes não saibam a real igualdade que cada um possui; "Resolução e Soluções Políticas", quando uma corrida armamentista não seria acionada por um aumento nas tensões, além de haver uma série de resoluções vindas da diplomacia e controle de armas (GRAY, 1971).

Concluímos então que uma Corrida Armamentista se define em um ambiente de rivalidade, no qual poderíamos procurar se os estados tem um objetivo que cause disputa entre eles. Sendo estes objetivos como territoriais e geográficos, de acordo com as necessidades econômicas, culturais ou de reputação do estado (RIDER, 2009). Ou também objetivos nos quais o estado lança uma estratégia que envolva um aumento no arsenal militar, e estes objetivos podem ser domésticos ou internacionais (GRAY, 1971).

Após identificarmos tais aspectos qualitativos podemos analisar o número de rivalidades que ocorreram no decorrer da história (THOMPSON, 2001), aplicar verificações baseadas na aquisição de armamentos, e aplicar modelos quantitativos nesse cenário (KYDD, 2000), além de verificar os tipos de armas e suas qualidades (GRAY, 1971). Finalmente após verificar os números e os possíveis objetivos e estratégias vindos de uma corrida armamentista, podemos analisar suas possíveis consequências (GRAY, 1971).

\section{Levantamento Empírico: Um continente de Rivalidades}

O senso comum consideraria que o continente sul-americano é um continente sem conflito ou que estes estariam superados. Entretanto, tal afirmação é equivocada. Primeiramente, devemos nos atentar ao fato de que a América do Sul se divide em regiões aonde as rivalidades são estáveis e outras instáveis. Com isso, o continente pode ser dividido em dois arcos, um da estabilidade que se concentra no MERCOSUL e outro da instabilidade que abrange a região Andino-Amazônica (HÉCTOR SAINT-PIERRE apud MEDEIROS FILHO, 2008 apud TEIXEIRA \& ANSELMO, 2011a). O mapa abaixo representa este esquema. 


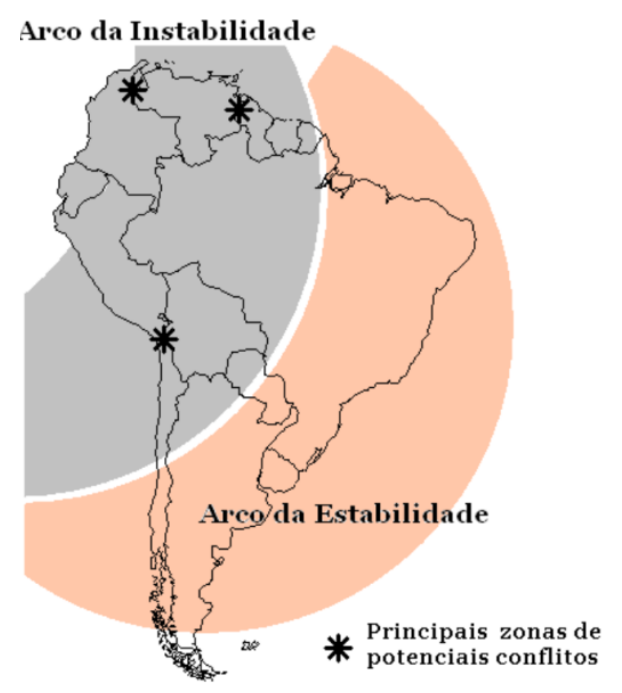

Fonte: MEDEIROS FILHO (2008) apud TEIXEIRA \& ANSELMO (2011a)

Em segundo lugar as rivalidades sul-americanas sofrem em determinados momentos de influências externas, países europeus têm interesses em determinadas áreas do continente, em especial na Amazônia (TEIXEIRA \& ANSELMO, 2011a). Já a presença dos EUA pode ser um fator que poderia estar alimentando a possível corrida armamentista no continente. Os EUA consideram, e sempre vão considerar a América Latina seu espaço de influência, com isso sua presença direta e indireta na América do Sul é grande. São mais de treze bases militares dos EUA espalhadas pelo continente sul-americano. Tal presença tem influência nas rivalidades estratégicas e pode ser um fator que contribuiu para o fenômeno aqui estudado (COSTA, 2009 apud TEIXEIRA \& ANSELMO, 2011a).

As "rivalidades estratégicas" do continente sul-americano têm raízes históricas profundas, todas têm origem no período colonial e chegaram até os dias de hoje. Estas rivalidades têm motivações que giram em torno de demarcação, ocupação e exploração econômica do território sul-americano.

No arco da estabilidade temos a rivalidade Platina, que envolve o Brasil e a Argentina, e como atores secundários Chile, Paraguai, Uruguai e Bolívia. Assim como foi exposto anteriormente, tal rivalidade começou na era colonial. Com a disputa entre as coroas portuguesas e espanholas pela bacia do Prata, a rivalidade foi transferida para os estados independentes no século XIX, sendo respectivamente a rivalidade entre Brasil e Argentina (TEIXEIRA \& ANSELMO, 2011a). Houve embates militares sangrentos neste período como o da Guerra do Paraguai, e a tensão se manteve na primeira metade do século XX em que se 
verificou tanto escaladas, como a de 1910 que quase resultou em uma guerra envolvendo o Chile, quanto mediações diplomáticas em prol da integração.

Na segunda metade do século XX a Argentina entraria em um processo de decadência econômica e política que os governos ora militares ou civis não conseguiam resolver e, ao mesmo tempo, queriam a preponderância na região (TEIXEIRA \& ANSELMO, 2011a). Com a decadência aumentando a partir dos anos 1970, o governo militar da época buscaria usar as rivalidades como válvula de escape das pressões políticas e sociais. As duas rivalidades a serem exploradas foram com o Brasil e com o Chile. Ambas as rivalidades quase escalonaram para uma guerra, porém nenhum destes acontecimentos acabou em guerra, o conflito com o Brasil se resolveria diplomaticamente com assinatura do Tratado Triparte, e um esforço diplomático do Papa João Paulo II ajudaria a acalmar a questão com o Chile.

No fim sobraria apenas uma rivalidade a ser explorada: a das ilhas Falklands/Malvinas, vinda de uma ocupação britânica do século XIX, que a Argentina considerou uma violação. Tal rivalidade domina o imaginário até os dias de hoje (TEIXEIRA \& ANSELMO, 2011a). Em 1982 a Argentina iniciaria uma guerra com a Grã-Bretanha pelas ilhas contando com apoio dos EUA. A derrota no conflito implodiria a economia do país, acabaria com o regime militar e destruiria a capacidade militar argentina que não se recuperaria até hoje. Por fim, a rivalidade se diluiria com a fraqueza da Argentina e a hegemonia da economia brasileira, abrindo assim caminho, para o estabelecimento do MERCOSUL.

Ainda que aparentemente superada, a rivalidade ainda existe, em especial com as ações danosas da Argentina no MERCOSUL. Há o fato também da presença estrangeira na região: o Paraguai possui duas bases militares dos EUA, uma delas próxima a tríplice fronteira (COSTA, 2009 apud TEIXEIRA \& ANSELMO, 2011a) Com isso, a região de certa forma permanece militarizada. No Brasil, o estado do Rio Grande do Sul é uma das regiões que desde os tempos coloniais recebe grandes parcelas dos ativos militares brasileiros, recebendo atualmente o grosso das forças blindadas e da força aérea do Brasil (TEIXEIRA \& ANSELMO, 2011a).

Com essa diluição, as tensões mais explosivas do continente foram transferidas para região amazônico-andina, constituindo o arco da instabilidade. A rivalidade entre Peru e Bolívia contra o Chile é uma das maiores rivalidades da região, e gira em torno da 
demarcação do deserto do Atacama e da exigência da Bolívia de uma saída para o mar. Ela passa a se consolidar após a Guerra do Pacífico 1879-1883 (LUENGO, 2012).

A guerra começou com uma ação boliviana, porém, esta só participou no inicio do conflito, depois a guerra seria centrada entre o Peru e o Chile, e terminaria quatro anos depois com o Chile vitorioso e este ocupando a capital do Peru, Lima (GONZÁLEZ, 2004). Nos anos que se seguiram ao final do século XIX e inicio do século XX houve vários processos diplomáticos por parte da Bolívia e do Peru a fim de recuperar os territórios perdidos na guerra. Em 1929 se assinaria um Tratado de Paz e Amizade entre o Peru e Chile, o Peru reconheceu as fronteiras terrestres com o Chile, porém não as marítimas, e este processo se arrastaria pelo resto do século XX.

Em 2008 o Peru iniciou um processo no Tribunal Internacional de Haia a fim de acabar com a disputa acerca da fronteira marítima (BAHTEN, 2013). O laudo só sairia em 2014 e demonstra como a rivalidade entre esses países está ainda ativa. Tal constatação também se pode fazer quando se levanta o caso do espião chileno "Oscar", este espião repassou informações ao Chile acerca das forças armadas peruanas durante o período de 2000 a 2009, período em que o Chile aumentou suas compras de armas (CASADO, 2014). Os efeitos desse conflito antigo estão presentes internamente até hoje nestes países, a vitória do Chile no passado fez com que sua identidade e suas fronteiras se consolidassem colaborando para seu desenvolvimento industrial (LUENGO, 2012). Já a Bolívia perderia sua saída para o mar travando seu desenvolvimento e alimentando governos instáveis que, por sua vez, alimentam o sonho de recuperar o território perdido, tanto é que atualmente a Bolívia iniciou um processo em Haia para recuperar sua saída ao mar.

Já o Peru além de perder territórios também se desestabilizou internamente, o conflito entre guerrilhas indígenas e o governo já foi apontado como tendo motivação no conflito do Pacífico (LUENGO, 2012). Ademais, seria interessante agora analisar o fator interno peruano. Desde o inicio do século XX o estado peruano enfrenta guerrilhas, tais movimentos ocorrem por conta das contradições sociais do país vindas de três variáveis: sua história, seu território e sua diversidade ética cultural (SORIA, 2007 apud POLLETO, 2009). Durante a década de 1930 as guerrilhas se associariam a ideologias marxistas e indígenas e esta seria sua principal característica no decorrer de sua história (POLLETO, 2009). 
A sucessão de governos militares peruanos reprimiria violentamente as primeiras gerações das guerrilhas até que, na década de 1970, surgiria uma nova geração de guerrilha mais radical, como o Movimento Revolucionário Tupac Amaru, e o Sendero Luminoso (POLLETO, 2009). Durante os anos 1980 o Peru passaria a ser uma democracia, porém, logo o país seria engolfado por uma crise inflacionária e econômica e ao mesmo tempo, as ações do MRTA e do Sendero Luminoso jogavam o país no caos.

Nos anos 1990, com o fracasso dos governos civis em lidar com situação, se abriria espaço para a figura de Alberto Fujimori, que em 1992 daria um autogolpe com apoio das forças armadas (POLLETO, 2009). Fujimori implementou duras ações contra o terrorismo, como a pena de morte para tal crime, além de iniciar um programa econômico ortodoxo para tirar o país da crise inflacionaria. Seus sucessos garantiriam sua reeleição em 2000, porém, escândalos de corrupção em 2001 o derrubariam, e o Peru pós-Fujimori passaria a adotar um governo de caráter Neoliberal.

Ainda assim o país passa por instabilidades políticas e econômicas, os grupos MRTA e Sendero Luminoso quase que desapareceram, mas estariam renascendo recentemente (POLLETO, 2009). O MRTA continua enfraquecido e seus quadros estão diminuídos a algumas dezenas, porém o grupo não desiste da luta armada mesmo que suas ações nem sejam mais classificadas como as de um grupo terrorista. O Sendero Luminoso estava em decadência, mas no governo pós-Fujimori o grupo teria passado por um revigoramento e agora estaria dividido entre uma facção que se recusa a negociar com o governo e se associa cada vez mais ao Narcotráfico.

A rivalidade entre Peru e Equador é marcada por conflitos militares. Desde o século XIX já foram ao menos três guerras (GONÇALVES, 1999). Os conflitos ocorreram na região de fronteira entre os dois países, sendo que a demarcação e exploração econômica desta região são a principal fonte dos conflitos. $O$ conflito teria duas características marcantes: a utilização de armamento moderno para o continente sul-americano, e as longas negociações diplomáticas que a partir dos anos 1940 tiveram franca participação da diplomacia brasileira.

A última guerra ocorreria em 1995 e novamente teria a utilização de armamento moderno por ambos os lados, caças Kfir e Mirage do lado equatoriano, e Migs e Sukhois do lado peruano. Após meses de combate e mais de mil mortes a guerra terminaria no mesmo ano por meio de uma intervenção diplomática brasileira (GONÇALVES, 1999). Por meio da 
"Declaração do Itamaraty", o Brasil procurou invocar compromissos diplomáticos já feitos no passado e montou uma missão de paz na região, a MOMEP. Em 1999 seria assinado um tratado de paz em Brasília, porém as tensões continuariam. Diversas vozes se levantaram em oposição aos acordos diplomáticos no Peru, houve até uma revolta popular que se instalou na região de Loreto próxima à região de conflito. No caso do Equador haveria problemas acerca da soberania equatoriana e de seu desejo de ter uma saída para o rio Amazonas.

Vale ressaltar um fato: os possíveis lucros do Brasil com o conflito de 1995 e suas mediações. As empresas IMBEL e EMBRAER teriam vendido armamentos para ambos os lados do conflito, além do esforço de se evitar que o conflito se internacionaliza-se o que teria aberto espaço para a entrada de empresas brasileiras na região. Fato que poderia se associar à construção da rodovia Transandina, que liga o Brasil ao Pacífico e foi concluída em 2006 (GONÇALVES, 1999). A tensão seria de certa forma resolvida com uma comissão binacional que acordou em retirar os efetivos militares da região em 2001 (PERON et. al., 2008).

Em 1999 o Equador entraria em crise econômica e adotaria políticas Neoliberais que agravariam a situação econômica e de crescimento humano baixo. A partir de 2003 uma franca crise política se instauraria no país derrubando dois presidentes e se mantendo até 2006 (PERON et. al., 2008). Rafael Correa é eleito em 2006 e passa a copiar o modelo de Hugo Chávez para o Equador, focando em nacionalizar o petróleo e estabelecer políticas sociais que venham a diminuir os conflitos sociais do país. As populações indígenas do Equador são os principais demandantes por mudanças sociais no país, além de terem uma situação conflituosa muito similar com a peruana.

Nesse contexto, o governo Correa lançou um plano de combate aos conflitos internos do país, o "Plano Equador". Tal plano focava as regiões de fronteira, em especial a fronteira com a Colômbia, que por conta da aplicação do "Plano Colômbia", traficantes de lá passaram a fugir para o Equador assim como um grande número de refugiados vindos do conflito (PERON et. al., 2008). Com isso o Equador passou a ser mais rígido com as violações de seu território o que acarretaria um aumento na tensão de sua rivalidade estratégica com a Colômbia. Colômbia e Equador possuem uma disputa de fronteira vinda do seu processo de independência, a Colômbia não aceitaria muito bem a separação do Equador, com isso os dois países chegariam a travar uma guerra em 1863 (MITRE, 2010). 
O "Plano Equador" procuraria desenvolver as regiões de fronteira, mas com a rigidez da vigilância da fronteira ocorreria o maior momento de tensão do continente sul-americano da última década. Em 2008 uma operação do exército colombiano mataria o número 2 das FARC em território equatoriano, tal violação levaria a mobilização de tropas na fronteira e o risco de guerra generalizada, pois envolveu a Venezuela também por sua afinidade com o governo equatoriano e sua rivalidade com a Colômbia (MARES, 2012). Tal acontecimento demonstra como a situação interna colombiana pode ter o fator decisivo para detonação de escaladas no continente, pois envolveu diversas rivalidades e riscos que excederam suas fronteiras.

A guerra civil na Colômbia é uma mistura de guerrilhas de esquerda e direita que começou nos anos 60 e o narcotráfico que iniciou sua trajetória nos anos 1970 (SANTOS, 2006). Nos anos 1990, a tensão explodiria e jogaria o país no caos com o governo contra as guerrilhas tanto de direita como de esquerda, e as guerrilhas e os narcotraficantes uns contra os outros. Em 1998 haveria o primeiro processo de paz com a guerrilha e combate direto do narcotráfico, porém ao lidar com os problemas separados a guerrilha se reagruparia e, desta forma, as negociações falhariam.

Em 2000 os EUA interviram e anunciariam o "Plano Colômbia", com isso a Colômbia passaria a ter presença militar direta dos EUA, além de ceder-lhe bases militares, com três ao menos em seu território (SANTOS, 2006). Entre 2002 e 2006 o bombardeio estratégico e a fumigação das plantações de coca fariam com que a guerrilha perca territórios e força. Somado a isso havia situação do governo de Álvaro Uribe que defendia as ações mais duras contra a guerrilha. Por mais que houvesse denúncias de violações dos direitos humanos os sucessos contra a guerrilha foram apoiados pela população que reelegeria Álvaro Uribe para um segundo mandato, e assim se manteve a política de combate à guerrilha.

O conflito na Colômbia permanece, porém, atualmente se tem havido conversações de paz que podem por um fim ao conflito, mas ainda há a elevação das tensões com a Venezuela. A rivalidade entre Venezuela e Colômbia vem da dissolução da Grã-Colômbia, porém nunca evoluiu para uma guerra (CERVO, 2003). Assim, durante o período do final do século XIX ao começo do XX, ocorreriam negociações que procurariam demarcar as fronteiras terrestres entre os dois países. Entretanto, não se demarcariam as fronteiras marítimas e, durante os anos 1960, ocorreria uma crise acerca da demarcação da fronteira marítima alimentada pelos rancores das decisões anteriores e pela exploração do petróleo na região. Tal questão 
permaneceria sem resolução até os dias de hoje, somando-se também os problemas com o controle da fronteira terrestre, em que há o tráfico de drogas, refugiados e a incursão de guerrilhas.

A subida de Hugo Chávez ao poder na Venezuela elevaria as tensões, por mais que se falasse que a iniciativa inicial de Chávez era de cooperação. Logo um conflito se instauraria na região por conta dos problemas de fronteira (CERVO, 2003). Em 2008 quase haveria uma guerra e, em 2009, novamente as tensões se elevariam, em decorrência de um acordo entre EUA e Colômbia (MARES, 2012). Tal situação ocorreu pelos seguintes fatores: A proposta bolivariana de Chávez, ao assumir o poder, de reconstruir a Grã-Colômbia que traz desconfianças das lideranças do vizinho, e a política do governo de Chávez em não considerar as FARC um grupo terrorista (CERVO, 2003).

O governo bolivariano não só elevaria as tensões das rivalidades estratégicas como também mudaria a situação interna da Venezuela radicalmente. Com Chávez no poder, a partir dos anos 2000, se quebraria a tradição democrática do país além da política de isolamento com relação ao resto da América Latina (PERON et. al., 2008). Assim como se iniciou um processo de reaparelhamento e reestruturação política das forças armadas, em que o presidente passou a ser o seu chefe supremo. Houve, também, a criação de milícias populares armadas e treinadas para combater um inimigo externo, este seria mais especificamente os EUA. A situação caótica em que a Venezuela se encontra após o falecimento de Hugo Chávez demonstram como suas atitudes anteriores levaram o país, e o subcontinente sul americano, a uma situação perigosa.

\section{Orçamentos}

Na primeira década do século XXI o gasto com defesa como um todo no continente girava em torno de US\$ 43,1 bilhões, e durante um breve período este valor não se alterou até que, em 2006, o gasto começa a crescer, chegando a quase 70 bilhões de dólares em 2012, data da última medição, (SIPRI, MILITARY DATABASE, 2013) Para se ter uma melhor forma de visualização de tais ondulações, a tabela abaixo irá procurar demonstrar os gastos exatos do período de 2000 a 2012. 


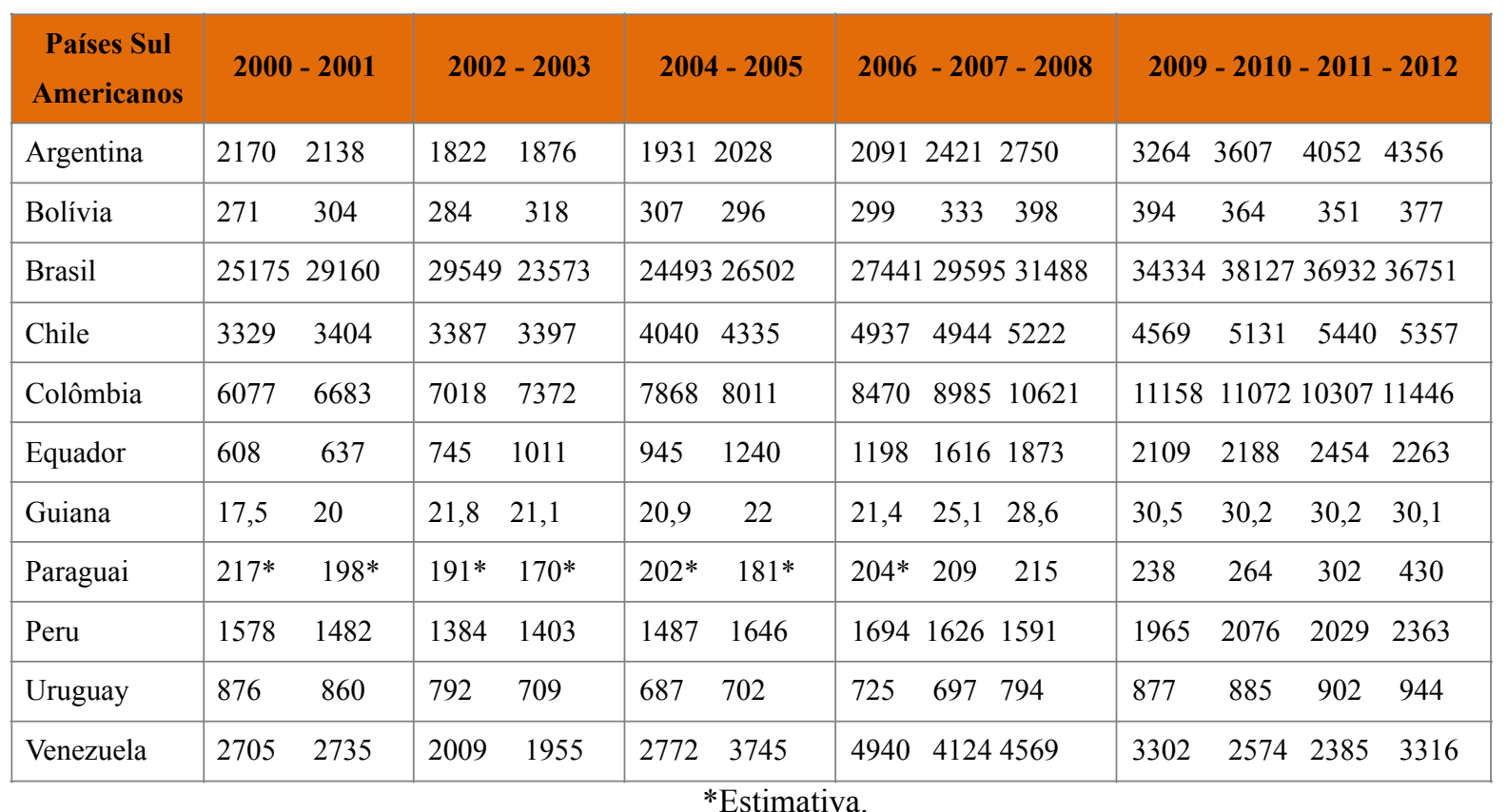

Fonte: SIPRI Military Database (2013)

Há outras formas pelas quais os países do continente sul-americano buscam financiar sua defesa, os recursos financeiros para tal tarefa advém de dividendos da exploração dos recursos naturais, das leis de financiamento por dívida, e de projetos de desenvolvimento nacional. A Venezuela possui mecanismos como a lei de endividamento ("Ley de endeudamiento"), financiamento por meio da dívida pública, o FONDEN ("Fondo de Desarollo Nacional"), recursos vindos do petróleo e do Banco Central, para financiar seus projetos militares (BROMLEY \& SOLMIRANO, 2012).

O Equador denota o caso mais curioso, além de suas forças armadas receberem dividendos da exploração do petróleo desde 1972, possuem investimentos em outras áreas (BROMLEY \& SOLMIRANO, 2012). Frutos de políticas desenvolvimentistas nos anos 1970, o exército equatoriano tem investimentos em áreas como mineração, aço, explosivos e agricultura, além de operar franquias de turismo na capital Quito.

O Chile é o caso mais clássico da utilização de dividendos da exploração dos recursos naturais para financiar a defesa, com sua "Lei do Cobre" que desde os anos 1950 impõe uma taxa sobre os lucros da exploração deste minério, indo direto para as forças armadas (BROMLEY \& SOLMIRANO, 2012). Durante o período militar a taxa cobrada subiu para $10 \%$ dos lucros, após a redemocratização se fizeram propostas em prol da diminuição deste montante, porém, o debate acerca de sua importância para a defesa do Chile se mantém até hoje. 
O Peru em 2004 criou mecanismos de financiamento similares ao chileno. Primeiro se criou um fundo especifico para as forças armadas e a polícia, com um financiamento de $\$ 25$ milhões vindos diretamente do tesouro nacional (BROMLEY \& SOLMIRANO, 2012). Junto com os fundos do tesouro, essa lei também previa a utilização de $20 \%$ dos royalties do campo de gás natural Camisea, que em 2006 subiu para 40\%, além dos 30\% do campo Lot 56, há a intenção do governo atual de subir ainda mais essa cifra.

O Brasil não têm mecanismos similares de financiamento da defesa, porém suas políticas públicas que buscam o desenvolvimento de tecnologia e infraestrutura acabam por financiar alguns projetos de suas forças armadas. Com a criação da Estratégia de Defesa Nacional brasileira em 2008, busca-se o desenvolvimento das áreas de cibernética, espacialmente nuclear com o aporte do PAC (Programa de Aceleração do Crescimento) (BROMLEY \& SOLMIRANO, 2012). Porém os cortes recentes no PAC criam preocupações acerca do futuro de tais projetos.

Uma última fonte de recursos para a defesa no continente sul-americano é a ajuda estrangeira, sendo EUA o principal doador de recursos por conta de seu interesse no combate ao narcotráfico e terrorismo (BROMLEY \& SOLMIRANO, 2012). O maior receptor de recursos vindos dos EUA é a Colômbia, por meio do "Plano Colômbia". O valor doado ao país entre 2000 e 2008 chegou à cifra de $\$ 6$ bilhões, a falta de transparência não nos permite saber aonde especificamente estes recursos foram alocados.

\section{Compra de Equipamentos}

A importação de armas nas Américas aumentou 34\% durante o período de 2003 a 2007, e entre 2008 a 2012 sua participação global na importação de armamentos cresceu de 10\% a 11\% (HOLTOM et.al. 2013). Porém, entre 2009 e 2013 tal participação voltou a ser de 10\%. EUA se mantêm o maior importador do continente seguido pela Venezuela.

A Venezuela é o maior importador de armas da América Latina, reflexo de seus projetos de rearmamento. Seus principais fornecedores são a Rússia, Espanha, Brasil, China e Ucrânia (PERON et. al. 2008). Como a Rússia supre 66\% das importações de armas do país, durante o período aqui estudado foram comprados armamentos como: 24 caças Sukhoi Su-30MK2V, sistemas de defesa antiaérea Tor-M1, helicópteros Mi-17B multi-role, helicópteros de ataque Mi-35 e helicópteros de transporte pesado Mi-26 Halo; cinco radares móveis e 100 mil fuzis 
AK-103 e as fábricas destes. Também foram compradas baterias antiaéreas S-300 e blindados BMP-3 e BTR-80, sistemas antiaéreos Pechora-2M SAM, tanques T-72 e canhões autopropulsados 2S19 MSTA-S e 2S23 Nona SVK (HOLTOM et. al. 2013). Da Espanha foram adquiridos Fragatas F-25 e F-26 da classe descoberta, quatro corvetas Tango 61 e Tango 62, 12 lanchas de deslocamento rápido dotadas de lançadores de mísseis, dois submarinos e seis aviões C-295 (PERON et. al. 2008).

As importações de armamentos do Brasil aumentaram 65\% nos anos aqui estudados. Os equipamentos têm suas origens em países como os EUA, a EU, as indústrias bélicas brasileiras, Israel e Rússia (WEZEMAN \& WEZEMAN, 2014). Entre 2006 e 2008, os projetos de modernização e aquisição de equipamento bélico novo começaram a avançar. Foram importados 12 aviões de transporte C-295M e dois aviões Lockheed P-3 Orion, provenientes da Espanha, foram comprados também 128 tanques Leopard 1a1 e 240 tanques Leopard 1A5.

Depois se adquiriram 12 helicópteros de ataque MI-35 da Rússia, 100 A-29 Super Tucanos, 50 helicópteros EC-725 Super Cougar, se fez a compra e construção de submarinos convencionais modelos Scorpene, e 3 navios-patrulha VT-90 da Grã-Bretanha (HOLTOM et. al. 2012). Mais a frente, o Brasil encomendou 2044 blindados Guarani da empresa Iveco, fabricados no Brasil, e em 2013 finalmente se optou pela compra, e fabricação no Brasil, de 36 aviões de caça JAS-39 Gripen-E NG (WEZEMAN \& WEZEMAN, 2014).

As compras militares feitas pelo Chile no período aqui estudado o fazem a nação sulamericana com as forças armadas mais modernas do continente. As armas chilenas têm origem nos EUA, EU e Israel (VILLA, 2008). Dentre essas armas estão 10 aviões de caça F-16C e 20 F-16AM, dois submarinos Scorpene, duas fragatas tipo Karel Doorman e duas do tipo Van Heemnskerck, de origem holandesa, ademais de três fragatas Type 23 Ex-Royal Navy do Reino Unido. Para o exército se comprou 136 tanques Leopard - 2, mísseis norteamericanos AIM-9M Sidewinder, AIM-120 AMRAAM, SeaSparrow e Harpoon, e os mísseis israelenses Derbys e Pyton 5, além de bombas inteligentes de vários calibres. Durante o período de 2009 a 2013 o Chile comprou também 12 aviões Super Tucano do Brasil, e mantém planos de comprar alguns equipamentos de origem russa (NETO, 2013).

O Peru durante o período de 2003 a 2007 procurou mais modernizar seus velhos armamentos do que adquirir novos, com isso reforçou seus laços com seus antigos 
fornecedores, sendo estes a Rússia, a França e a China (VILLA, 2008). O Peru buscou a modernização de seus submarinos IKL 209/1200, assinou contratos para a modernização de seus aviões MIG 29, SU-25 e Mirage 2000 e de seus numerosos tanques T-55 e AMX-13. Em 2009, o Peru anunciou planos de adquirir 80 tanques MBT-2000, além de intenções de comprar tanques e blindados novos da Rússia (HOLTOM et. al. 2010).

A Colômbia, apesar de ter um exército de 300 mil homens e altos gastos militares, é defasada em aviões de combate e blindados, somente a partir de 2008 esse quadro começou a reverter. Os principais fornecedores de armas do país são os EUA, Espanha, Brasil, Itália e Canadá (VILLA, 2008). As armas compradas pela Colômbia antes de 2008 se resumiam a diversos helicópteros UH-60L Black Hawks dos EUA, vários aviões Super Tucano do Brasil e lanchas de patrulha fluvial (VILLA, 2008). Em 2008, a Colômbia procurou modernizar suas forças armadas a fim de alcançar os outros países sul-americanos. Nos anos subsequentes foram comprados mais 35 helicópteros UH-60L Black Hawks dos EUA, além de receberem um upgrade de mísseis israelenses Spike-MR (WEZEMAN \& WEZEMAN, 2014).

Também de Israel foram comprados 13 aviões de combate Kfir armados com bombas guiadas Griffin, e aviões de reconhecimento não tripulados Hermes-900 e Hermes-450, assim como 32 veículos blindados STRYKER M1126 encomendados do Canadá (WEZEMAN \& WEZEMAN, 2014). O Equador teve um crescimento de $366 \%$ nas importações de armas no período de 2001 a 2010, porém, mesmo com esse crescimento o país não chega a superar importações de outros países sul-americanos (HOLTOM et. al. 2011). Grande parte das armas adquiridas pelo Equador vem de transferências originadas em outros países do continente. No período de 2006 a 2010, o país recebeu 2 fragatas usadas modelo Leander do Chile, 16 dos 18 aviões de combate e treinamento EMB-314 Super Tucano do Brasil, e 6 aeronaves de combate de segunda mão Mirage-50 doadas da Venezuela.

Para fecharmos o levantamento de dados acerca da compra de armas na América do Sul no período estudado, podemos ressaltar que países menores como Bolívia, Paraguai e Uruguai não adquiriram armamento significativo. A Argentina não compra armamentos novos há décadas. Somente em 2012 o país demonstrou a intenção de comprar 14 blindados Guarani do Brasil (HOLTOM et. al. 2013). 


\section{Resultados}

Com o levantamento dos dados teóricos e empíricos completos podemos agora partir para a relação de ambos os dados para organizarmos o cenário sul-americano. Primeiro devemos ressaltar que a América do Sul possui uma vasta quantidade de rivalidades estratégicas nos moldes de disputa territorial. Tais rivalidades estão mais concentradas no arco da instabilidade que compreende todo o norte do continente. A primeira rivalidade que devemos considerar é a do Chile com o Peru e a Bolívia.

Tal disputa territorial, como foi descrita, abrange todas as três motivações levantadas no capítulo teórico, sendo que Bolívia e Peru tem rancores culturais acerca da perda de territórios na Guerra do Pacífico. Já o Chile tem nessas conquistas um fator crucial para a formação de sua identidade, com isso o fator de reputação onde o país busca manter os territórios conquistados no passado, e onde há a eterna desconfiança e vigilância com relação aos vizinhos. Com relação à rivalidade entre Peru e Equador, esta também está relacionada com a demarcação de territórios, mas somente evoluiu para uma rivalidade cultural, verificada nas demonstrações violentas no Peru, após a guerra de 1995.

Podemos comprovar que a disputa que o Peru tem, com seus vizinhos, possui todos os aspectos que pode haver em uma rivalidade estratégica. Sendo aspectos tangíveis o fato de todas elas terem uma motivação territorial econômica, e intangível pelo fato de ambas terem evoluído para uma rivalidade cultural que se liga à identidade destas nações. $\mathrm{O}$ aspecto de reputação aparece no fato do Peru encorajar a retomada dos territórios perdidos para o Chile, e no seu desejo de expansão para o Equador. Com isso as rivalidades peruanas passam a ser um fator crucial para o país, sendo que, se não forem resolvidas ameaçam a existência do país.

Indo para o norte, temos novamente duas rivalidades relacionadas à disputa de fronteiras: a disputa entre Equador e Colômbia tem raízes no processo de formação de ambos os países, sendo uma rivalidade que evoluiu de um aspecto territorial para um aspecto cultural. Podemos comprovar isso pelo fato desta rivalidade ser extremamente explosiva, mesmo que tenha somente ocorrido uma guerra, o caso de 2008 demonstra como a rivalidade está ativa e, de certa forma, ligada ao fator interno de ambos os países.

Se observarmos outra rivalidade relacionada ao caso de 2008, a da Venezuela versus Colômbia, observaremos uma situação quase semelhante à do Equador, porém, com algumas 
peculiaridades. O conflito originário da dissolução da Grã-Colômbia nunca teve uma guerra, porém, por mais que se efetivassem acordos diplomáticos acerca das fronteiras terrestres,- não se conseguiu um consenso acerca das fronteiras marítimas nem uma resolução dos problemas que ocorrem na fronteira. Vale ressaltar o desejo atual da Venezuela de restaurar a GrãColômbia de acordo com sua visão, e com isso temos uma rivalidade territorial que evoluiu para uma cultural e que, agora, se torna de uma categoria de reputação.

Em sua totalidade, poderíamos dizer que as rivalidades da sub-região do Prata foram superadas por meio de negociações e pelo processo histórico, porém, isto seria ignorar a longa história que a acompanha. Argentina e Brasil, por mais que sejam integrados com o MERCOSUL, ainda têm uma visível rivalidade cultural, fato que pode ser comprovado nos atritos que os dois países têm acerca da condução do MERCOSUL. A sub-região do Prata não tem tensões similares ao do arco da instabilidade, porém, se verifica que ainda é uma região militarizada e com conflitos, não militares, mas de terras e ambientais.

Antes de adentrarmos no fator interno devemos observar que, de acordo com a teoria de Rider (2009), as rivalidades mais explosivas aqui listadas podem estar enviando sinais a seus adversários a fim de resolver suas questões no âmbito de escalada armada. Ademais, os conflitos internos de Colômbia, Peru, Equador e Venezuela também são importantes para termos resultados acerca da existência de uma corrida armamentista. O conflito colombiano ficou mais grave nos 1990 e levou à intervenção dos EUA no país na virada do século. Isto levou a atitudes mais duras por parte da Colômbia contra a guerrilha, e a desconfiança de seus vizinhos acerca da presença direta dos EUA no país.

Tal tensão seria alimentada também por problemas vindos diretamente do conflito na Colômbia, como refugiados na região de fronteira, fuga das guerrilhas e narcotraficantes para os vizinhos, e as violações de territórios destes países por parte da Colômbia. Ainda assim, atualmente a situação interna colombiana parece ser a que mais tem se estabilizado no continente com a guerrilha extremamente enfraquecida, por ser a economia que mais cresce no continente, e por contar com um processo de paz, ainda que lento.

O mesmo não pode se dizer dos vizinhos da Colômbia, como o Peru, que teve sua existência ameaçada pelos grupos terroristas MRTA e Sendero Luminoso durante os anos 1980, mas conseguiu sobreviver por meio de ações duras próprias nos anos 1990. Mesmo que a dura repressão do estado peruano tenha que praticamente exterminado os grupos terroristas, 
atualmente o país vive assombrado com o renascimento do narcotráfico e da guerrilha ainda mais associada ao tráfico de drogas.

O Equador vive uma situação quase similar ao Peru, porém, com variáveis internas diferentes. O país tem crises indígenas e sociais muito parecidas com as do Peru, porém, não tem guerrilhas, mas sofre invasões das guerrilhas dos vizinhos, somado a isso há a economia frágil cada vez mais dependente da exportação de hidrocarbonetos e do exército. O domínio do exército equatoriano sobre a economia do país é algo peculiar, pode ser um subproduto das antigas políticas desenvolvimentistas ou dos problemas de fronteira do Equador, com isso a sociedade equatoriana continua militarizada e com um futuro econômico incerto.

A situação interna mais preocupante atualmente é a venezuelana, desde o começo do governo bolivariano este tem armado milícias bolivarianas a fim de proteger o país de inimigos externos. Após a morte do Hugo Chávez, a Venezuela tem se dividido cada vez mais, assim como o fim da tradição democrática do país tem causado um conflito entre a sociedade e o governo, e da sociedade entre si. Não se tem noticia sobre a oposição do país se armar, mas com os resultados econômicos cada vez piores, somados à tensão interna, podem ser sinais de uma possível escalda interna no país.

Na região do arco da estabilidade não se verifica tais situações de convulsões internas, somente o medo de prováveis distúrbios indígenas na Bolívia. Porém, o Brasil é o país que mais se preocupa com os problemas internos dos vizinhos, pois teme que estes problemas aumentem a presença estrangeira no continente, prejudiquem os seus interesses e adentrem suas fronteiras.

Adentrando no fator quantitativo, temos que no ano de 2003 foi o ano onde os gastos militares no continente passaram a aumentar. Se ligarmos com o ano de 2000, onde houve a implementação do "Plano Colômbia", veremos que logo após o aumento de gastos de 2003, e por volta de 2005, começam as aquisições de armamentos novos por diversos países da América do Sul. A ideia mais aceita seria a de que tais aquisições ocorrem por conta do desenvolvimento econômico, porém, os modelos de "Dilema do Prisioneiro" e "Espiral" nos dizem o contrário.

Relembrando que o "Dilema do Prisioneiro" coloca que os estados não valorizam as recompensas vindas da cooperação se não tiverem sistemas de defesa decisivos. Tal cenário poderia ser verificado na situação da aquisição de aviões de combate F-16C e SU-30MK pelo 
Chile e Venezuela, respectivamente, que teriam criado desconfianças nos vizinhos e detonado processos de renovação na área no Brasil, Peru e Colômbia, ainda que lentos. Com relação ao modelo de "Espiral", este considera que os países têm medo da mudança do status quo. A implementação do "Plano Colômbia" pode ter detonado uma espiral de desconfiança no continente acerca da presença estrangeira.

Entrando agora na qualidade dos armamentos, observarmos mudanças nos tipos de armamentos comprados pelos países sul-americanos. A Colômbia tem um grande exército e uma extensa frota de helicópteros, porém, é defasada em termos técnicos em aviões de caça avançados e blindados. Entretanto, a partir do ano de 2008, começou a haver mudanças nas aquisições das forças armadas colombianas. O país passou a adquirir aviões de caça avançados Kfir e blindados canadenses. Tal mudança se deve, muito provavelmente, com as relações conflituosas com a Venezuela, que adquiriu armamento mais pesado antes das crises de 2008, como tanques T-72 e fragatas espanholas. Vale ressaltar uma questão no fator qualitativo de armamentos, a aquisição de 100 mil fuzis AK-103 pela Venezuela. Os relatos de que este armamento foi repassado às FARC torna a relação entre esses dois países mais conflituosa.

Com relação aos outros países, o Equador é o país em que mais se verificou uma militarização, porém, suas armas adquiridas são antiquadas e ultrapassadas. O curioso da aquisição de armamentos equatoriana é o fato de que grande parte deles vieram de doações de outros países sul-americanos, seguindo a lógica de rivalidades estratégicas. O Equador recebeu fragatas usadas Leander do Chile, e aviões de combate, também usados, Mirage 50 da Venezuela. Considerando que o Equador é rival do Peru e da Colômbia, é passível que os outros dois rivais, respectivamente, destes países doem armamentos ao Equador. Já a dinâmica armamentista entre Peru e Chile demonstra como o Peru está atrasado em relação ao moderno exército chileno. A reação peruana teria começado com a criação, em 2008, de mecanismos de financiamento das forças armadas por meio de dividendos da exploração de hidrocarbonetos. Os resultados desta ação somente serão verificados no futuro se as intenções de aquisição de armamentos novos por parte do Peru realmente se concretizarem.

A qualidade dos armamentos brasileiros é a que menos tem a ver com as rivalidades estratégicas do continente sul-americano. Por mais que o Brasil tenha demasiadamente demorado a adquirir armamentos modernos, os projetos de aquisição e desenvolvimento 
nacional de seus equipamentos de defesa são voltados para o possível combate a elementos de fora do continente. A compra e construção dentro do Brasil dos submarinos Scorpene, do submarino nuclear, e de caças JAS-39 Gripen-E NG, denotam a intenção de recuperar o tempo perdido da falta de reaparelhamento das forças armadas, de desenvolver a indústria nacional e de aumentar o poder do Brasil no cenário internacional.

Após relacionar os dados empíricos com as premissas teóricas de corrida armamentista, podemos então partir para uma conclusão que responda à questão norteadora deste estudo, além de traçar os possíveis cenários futuros do continente.

\section{Conclusão}

A partir deste estudo podemos entender as dinâmicas bélicas do continente, com isso a hipótese debatida é verdadeira, isto é, a corrida armamentista no continente existe e esta não é algo único e constante, mas pontual e temporal, e se, confirma pelos levantamentos e resultados obtidos. Portanto, as escaladas armadas ocorrem temporalmente e pontualmente dentro das rivalidades estratégicas de cada país sul-americano, tendo momentos de tensão de tempos em tempos. Durante esta década, tivemos o escalonamento de ao menos três grandes rivalidades estratégicas e, a partir daí, os fatores de renovação de arsenais, desenvolvimento da indústria de defesa, desenvolvimento econômico e presença militar estrangeira direta contribuíram para o aumento da escalada no período.

Assim a corrida armamentista ocorreu detonada por fatores como presença estrangeira direta e renovação de arsenais militares, suas consequências são a continuidade desta, mudança de algumas políticas externas e a deterioração interna de alguns países. O papel do Brasil neste fenômeno poderia ser considerado secundário, porém, não é o que se verifica ao analisarmos mais a fundo.

O Brasil busca não passar a imagem de imperialista a seus vizinhos, mas, seu crescimento econômico e a necessidade de renovação de seus arsenais militares, criam um desafio para este esforço. O país passa então a aumentar seu arsenal, porém, sem um grande aumento que gere uma possível desconfiança no continente, ao mesmo tempo em que a escalada armamentista cria possibilidades de lucro e para o exercício de liderança na América do Sul. Há movimentos de expansão da indústria bélica brasileira para integração com os vizinhos e, na questão diplomática, o Brasil procura ser um instrumento apaziguador de tensões. 
Tal forma de ação é curiosa, pois as tensões do continente prejudicam os processos de integração, porém, uma observação pode ser feita. Se o Brasil é realmente um instrumento apaziguador, como o teria sido nas crises do Equador, este poderia estar procurando exercer um poder de liderança ao mesmo tempo em que explora as rivalidades para obter lucros e influência no continente, assim como foi com as potências estrangeiras no passado.

Com toda a dinâmica exposta aqui, podemos lançar mão dos possíveis cenários futuros para a região utilizando a tipologia qualitativa de Colin S. Gray (1971) descrita anteriormente. Primeiramente, o Brasil e o Chile possuem uma "Superioridade Clara" sobre os vizinhos e rivais, enquanto países como Peru e Equador têm uma "Inferioridade Marginal" e buscariam ao menos uma "Paridade" com os rivais. Já a Colômbia, se observada pelos seus números, se encaixaria na categoria de "Superioridade Clara", porém, analisando mais a fundo seus objetivos e gastos, vemos que não é o caso. Desta forma, colocando-a junto com a situação venezuelana, teríamos uma situação de 'Paridade", em que ela e seus adversários buscam uma igualdade de termos quantitativos e qualitativos para obter ganhos diplomáticos.

Desta forma, os países de "Inferioridade Marginal", como Peru e Equador, por suas defasagens técnicas e problemas internos, buscam "Paridade" a fim de manter o status quo e garantir possíveis ganhos diplomáticos no futuro. Com isso um conflito armado seria muito difícil de ocorrer e, a primeira vista, poderíamos considerar que as rivalidades no arco da instabilidade têm escaladas armadas, mas não tão grandes para ocorrer uma guerra. Porém, isto seria desconsiderar o fator mais explosivo atualmente no continente: a Venezuela.

As rivalidades venezuelanas foram as que mais escalonaram na última década, porém, seu fator mais perigoso não são suas rivalidades, mas sua situação interna caótica. Observando que as duas primeiras consequências do modelo qualitativo são a "Guerra" e a "Exaustão/Falência" do estado, a situação interna venezuelana aparenta ter fortes tendências de levar o país a uma destas consequências. A situação econômica e política se deterioram cada vez mais desde a morte de Hugo Chávez, e ainda assim o país mantém seus planos de compra de mais armamentos causando preocupações no continente. Aplicando o modelo qualitativo poderíamos supor que a Venezuela está com medo da falência do estado e está considerando a guerra e seus possíveis ganhos compensatórios para salvar o regime vigente.

Desta forma, o país buscaria entrar em guerra com um de seus rivais, contando com o apoio de países governados pela esquerda radical e com uma lógica de dissuasão para outros 
países. A lógica da dissuasão seguiria o que foi descrito na teoria qualitativa como dispositivo suicida, mas nesse caso, seria a preparação para a guerra, em que a Venezuela causaria muitos danos mesmo sendo derrotada e assim evitaria uma possível intervenção. Ainda assim, tais planos seriam difíceis de serem concretizados, pois as importações de armas do país dependem dos preços do petróleo, agora em baixa, e há dúvidas acerca da real capacidade da Venezuela em empregar as armas recentemente adquiridas.

Porém, há ainda uma consequência qualitativa na situação venezuelana mais possível de ocorrer, e até mesmo mais preocupante. A "Exaustão/Falência" do estado venezuelano é uma possível consequência, pois a situação interna caótica e a possibilidade de dispersão dos arsenais militares venezuelanos a tornam um catalisador de uma guerra interna, que excederia as fronteiras do país. Já houve denúncias de que armas adquiridas pela Venezuela teriam ido a parar nas mãos das FARC na Colômbia. Com isso, uma implosão do estado venezuelano não só causaria uma guerra civil, mas também dispersaria armas de seu arsenal para grupos armados de outros países ameaçando a paz interna de países como Peru e Colômbia.

Resgatando o texto de Carlos Teixeira da Silva (2007), apresentado na introdução deste trabalho, se colocou a possibilidade de que um conflito interno na Bolívia se espalhe e torne propícia a intervenção estrangeira com a justificativa de proteger minorias, mas também para tomar recursos naturais. Ao invés de um conflito na Bolívia, o que temos é um conflito na Venezuela, e com uma possibilidade ainda maior de se espalhar por conta de seu arsenal militar e caráter ideológico. Este poderia iniciar uma reação em cadeia que atingiria a região do arco da instabilidade e criaria uma zona de conflito que, por sua vez, ameaçaria as fronteiras do Brasil e daria motivos para intervenções estrangeiras.

Esse é o pior cenário possível, porém, não é inevitável, já que a situação interna colombiana ruma para um possível acordo de paz com boas projeções de crescimento econômico, e Equador, Peru e Bolívia apresentam problemas internos gravíssimos, mas não aparentam um colapso. Por mais que a violência se agrave cada vez mais na Venezuela, ainda há a possibilidade desta não explodir em uma guerra interna ou externa e se estabilizar. Vale ressaltar ainda que a teoria qualitativa tem outra consequência passível para a Venezuela: a derrota. O país abandonaria suas escaladas de armas por não ter mais meios para continuá-la, sendo isto uma forma do governo atual sobreviver ou ser substituído por outro menos belicoso. 
Ainda que haja a possibilidade de estabilização, devem-se levar em conta os piores cenários possíveis, pois esta não seria a primeira vez que um país sul-americano em processo de falência toma atitudes belicosas. A Argentina, como foi descrita anteriormente, estava em processo de decadência e buscou como válvula de escape entrar em uma série de tensões com os rivais culminando em uma guerra desastrosa e na implosão do país, com efeitos sentidos até hoje. Levando em conta o que foi discorrido acima, podemos levantar uma última possibilidade sobre o futuro das rivalidades e conflitos da América do Sul. Por mais que diminuída a rivalidade do Prata, ela ainda existe. São frequentes as reclamações no Uruguai e no Brasil acerca dos bloqueios econômicos e violações de tratados por parte da Argentina, sendo que a situação interna argentina se mantém caótica. Desta forma, podemos levantar uma seguinte questão: há a possibilidade de um governo nacionalista argentino subir ao poder e reascender as tensões platinas? Vale lembrar novamente que a Tríplice Fronteira se mantém militarizada, que há conflitos econômicos na região e que há uma presença estrangeira no Paraguai.

Sintetizando o pensamento destas considerações finais, a corrida armamentista existe, com sua pontualidade de acordo com cada uma das rivalidades estratégicas. O Brasil estaria fora deste cenário, porém, sua busca por hegemonia no continente e as possibilidades, tanto benéficas como maléficas, da escalada armada, fazem com que o país tenha que atuar amplamente nesta situação. Existem tensões graves, mas não a garantia certa de que estas irão se tornar conflitos diretos.

\section{Referências bibliográficas}

BAHTEN, G. L. V. Etapas finais do conflito de delimitação da fronteira marítima Chile-Peru perante a Corte Internacional de Justiça. Conjuntura Global, p. 3-7, 2013.

CASADO, José. Fim de guerra. Jornal O Globo, Rio de Janeiro, p. 1, 14 de Janeiro 2014. Disponível em: <http://oglobo.globo.com/opiniao/fim-de-guerra-11288021>. Acesso em: 10 Julho 2014.

CERVO, A. L. A Venezuela e seus vizinhos. In: CARDIM, S. P. G. \&. C. H. Venezuela: Visões brasileiras. Brasília: Instituto de Pesquisa de Relações Internacionais-IPRI, 2003. p. 157-181.

GONÇALVES, R. P. Fronteira Peruano-Equatoriana: Acordos de Paz e Mediacao Brasileira de 1995. E-revista, p. 1-10, 1999. 
GONZÁLEZ, S . La tercería boliviana y el problema de la mediterraneidad. Revista Fuerzas Armadas y Sociedad, Año 18, N. 1-2, p. 23-36, 2004.

GRAY, C. S. The Arms Race Phenomenon. World Politics, No. 1. ed. [S.1.]: Cambridge University Pres, Vol. 24, Oct., 1971.

KYDD, A. Arms Race and Arms Control: Modeling The Hawk Perspective. University of California, Riverside: Midwest Political Science Association, v. 44, No.2, 2000.

LUENGO, M. E. R. La Política Exterior de Chile Durante la Guerra y post-guerra del Pacífico (1879-1891): Las relaciones con Estados Unidos y Colombia. Diplomacia, Opinión Pública y Poder Naval. Valladolid: Universidad de Valladolid, 2012.

MARES, D. R. Por que os latino-americanos continuam a se ameaçarem o uso da força militar nas relações intra latino-americanas. VARIA HISTORIA, p. 599-625, 2012.

MITRE, A. Ligações perigosas: Estado e Guerra na América Latina. Plataforma Democrática, p. 1-29, 2010.

NETO, W. A. D. Diagnóstico da Segurança Regional Sul-americana. In: IPEA Boletim de Economia e Política Internacional. 1' ${ }^{\text {a }}$ ed. Brasília: IPEA, v. 13, 2013. Cap. 1, p. 5-17.

HOLTOM, P.; BÉRAUD-SUDREAU, L.; BROMLEY, M.; WEZEMAN, P. D.; WEZEMAN, S. T. Trends in International Arms Transfers, 2010. Estocolmo: SIPRI, 2011.

HOLTOM, P.; BROMLEY, M.; WEZEMAN, P. D.; WEZEMAN, S. T. Trends in Inter national Arms Transfers, 2009. Estocolmo: SIPRI, 2010.

Trends in International Arms Transfers, 2011. Estocolmo: SIPRI, 2012.

Trends in International Arms Transfers, 2012. Estocolmo: SIPRI, 2013.

PERÓN, Alcides Eduardo Dos Reis; TAVARES, Aurora Moreira Sampaio; ANTONIOLLI, Bruno Barreto; AMUSQUIVAR, Érika Laurinda; RINALDI, Patrícia Nogueira; BORGES, Thiago Mendes. A assim chamada "Corrida Armamentista" e os conflitos transnacionais na América Latina. Campinas: SAEI, 2008.

POLETTO, R. D. S. Terrorismo e Contra-Terroismo na América do Sul: As políticas de segurança na Argentina Colômbia e Peru. Universidade de Brasília, Instituto de Relações Internacionais. Brasília, p. 217, 2009.

RIDER, T. J. Understanding Arms Race Onset: Rivalry, Threat and Territorial Competition. The Journal of Politics, Vol. 71, n. 2, 2009.

SANTOS, M. O Plano Colombia e o Primeido Mandato de Álvaro Uribe (2002-2006). Cena Internacional, Vol. 8, $\mathrm{n}^{\circ}$ 2, pp. 63-83, 2006.

SILVA, Francisco Carlos Teixeira da. A Amazônia e as Novas Ameaças Mundiais. PADECEME, n. 16, p. 84-92, 2007. 
SIPRI Military Expenditure Database, 2012. Disponível em: <http://milexdata.sipri.org>.

BROMLEY, M; SOLMIRANO, C. Transparency in Military Spending and Arms Acquisitions in Latin America and the Caribbean. Policy Paper n. 31, STOCKHOLM INTERNATIONAL PEACE RESEARCH INSTITUTE (SIPRI), January 2012.

TEIXEIRA, Vinícius M.; ANSELMO, Rita de Cássia M. de Souza. Integração e conflitos na América do Sul A Fronteira Amazônica. Horizonte Ciéntifico, Vol. 5, N. 2, p. 1-30, Dezembro 2011 [2011a].

TEIXEIRA, Vinícius M.; ANSELMO, Rita de Cássia M. de Souza. América do Sul: O papel dos conflitos na perspectiva de integração do continente. Horizonte Ciéntifico, p. 1-28, 2011 [2011b].

THOMPSON, W. R. Identifying Rivals and Rivalries. Oxford: Blackwell Publishers, 2001.

VILLA, Rafael Duarte; VIGGIANO, Juliana. Trends in South American weapons purchases at the beginning of the new millennium - Tendências para as compras de armas na América do Sul no início do novo milênio. Revista Brasileira de Política Internacional, vol. 55, n. 2, p. 28-47, 2012.

VILLA, Rafael D. Corrida Armamentista ou modernização de armamentos na América do Sul: estudo comparativo dos gastos militares. Estudos de Cenários, p. 1-55, 2008.

WEZEMAN, S. T.; WEZEMAN, P. D. Trends in International Arms Transfers, Estocolmo: SIPRI, 2014. 